\title{
Enhancement of pure titanium localized corrosion resistance by anodic oxidation
}

\section{Davide PRANDO ${ }^{1}$, Davide NICOLIS ${ }^{2}$, Andrea BRENNA ${ }^{3}$, Maria V. DIAMANTI ${ }^{4}$, Mariapia PEDEFERRI ${ }^{5}$, Marco ORMELLESE ${ }^{6}$}

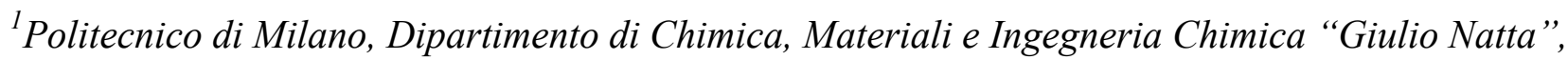 \\ Milan,Italy,davide.prando@polimi.it \\ 2 Politecnico di Milano, Dipartimento di Chimica, Materiali e Ingegneria Chimica "Giulio Natta", \\ Milan, Italy,davide1.nicolis@mail.polimi.it \\ ${ }^{3}$ Politecnico di Milano, Dipartimento di Chimica, Materiali e Ingegneria Chimica "Giulio Natta", \\ Milan, Italy,andrea.brenna@polimi.it \\ ${ }^{4}$ Politecnico di Milano, Dipartimento di Chimica, Materiali e Ingegneria Chimica "Giulio Natta", \\ Milan, Italy, mariavittoria.diamanti@polimi.it \\ ${ }^{5}$ Politecnico di Milano, Dipartimento di Chimica, Materiali e Ingegneria Chimica "Giulio Natta", \\ Milan, Italy,mariapia.pedeferri@polimi.it \\ ${ }^{6}$ Politecnico di Milano, Dipartimento di Chimica, Materiali e Ingegneria Chimica "Giulio Natta", \\ Milan, Italy,marco.ormellese@polimi.it
}

\begin{abstract}
The corrosion behavior of commercially pure titanium (UNS R50400) was investigated in presence of aggressive, bromides containing, species; reported to cause severer localized corrosion compared to chlorides. To enhance localized corrosion resistance of the metal, several surface treatments were performed. Samples anodized at potentials between $10 \mathrm{~V}$ and $200 \mathrm{~V}$ were characterized in term of oxide thickness and morphology and tested with potentiodynamic analyses in $\mathrm{NH}_{4} \mathrm{Br}$. This treatment was found to greatly enhance corrosion resistance of titanium but it suffers localized removal of the oxide due to wrong handling of the part before their installation. For this reason, another treatment, suitable for in-situ surface recovering was developed through chemical oxidation in $\mathrm{NaOH} 10 \mathrm{M}$.
\end{abstract}

Keywords

Titanium, anodizing, chemical oxidation, surface treatment 


\section{$\underline{\text { Introduction }}$}

Titanium has outstanding corrosion resistance due to a thin, amorphous, non-stoichiometric $\mathrm{TiO}_{2}$ protective layer ( $\max 10 \mathrm{~nm}$ thick [1]) that is formed spontaneously on the surface when exposed to aerated environment. This protective layer is very stable and allows the use of titanium in severe working conditions, such as offshore (up to $260^{\circ} \mathrm{C}$ ), acid environment, aerospace [2,3], automotive, high temperature, chemical \& food industry [4-6], marine hydrometallurgical application and nuclear fuel wastes containment [7-10], where no other metal can be used.

Nevertheless, commercially pure titanium may suffer different form of corrosion in very severe environments. Generalized corrosion is caused by small quantity of fluorides ions (more than 0.002 $\mathrm{M}$ [11]) that combining with titanium forms $\mathrm{TiF}_{4}$, destroying passivity film. Hydrogen embrittlement happens prevalently on alpha and alpha plus beta titanium due to their low hydrogen solubility in $\alpha$ $\mathrm{Ti}$ [12], stress corrosion cracking can also happen in very specific environments, such as anhydrous methanol, nitrogen tetroxide $\left(\mathrm{N}_{2} \mathrm{O}_{4}\right)$, red-fuming nitric acid or solid cadmium. [13] However, the most critical forms of corrosion of titanium are due localized breaking of passive layer and this is favored by the presence of concentrated halides, such hot salty water (above $200^{\circ} \mathrm{C}$ ) or bromide containing species $[14,15]$. To overcome this weakness, corrosion resistance enhancing treatments can be performed. It is the case of inclusion of elements that promote cathodic reaction, raising cathodic polarization curve above the critical active anodic curve at higher potentials in the passive region, such as palladium [16], or nitration, that consist in introducing nitrogen in the first $\mu \mathrm{m}$ of the surface to promote the formation of TiN and increase corrosion resistance. [17, 18] These methods, acting on titanium composition, are effective but complicated to perform and expensive as well other surface coating techniques, such as vacuum plasma spray coating, plasma spraying and chemical vapor deposition. [19] For this reason, treatments that act on the naturally formed passive layer are preferred. The easiest and cheapest treatment to tune oxide layer is anodic oxidation, that consists in applying an anodic polarization of several tens of volts to the metal, promoting the growth of the natural oxide layer with thicknesses from about $40 \mathrm{~nm}$ with anodizing potential $10 \mathrm{~V}$, to about 250 $\mathrm{nm}$ at $100 \mathrm{~V}$. [20-22]. At potentials higher than $100 \mathrm{~V}$ the anodizing begins to cause microarcs in the insulating oxide layer; in this regime, called "anodic spark deposition (ASD)" or "plasma electrolytic oxidation (PEO)", the oxide grows much more, reaching the thickness of several micrometers but switching from a compact to a porous structure. [23]

Due to promising results in increasing corrosion resistance obtained with anodizing treatments, in this work the effect of the anodizing potential has been investigated, ranging from $10 \mathrm{~V}$ to $200 \mathrm{~V}$, to define a treatment procedure able to delay or remove localized corrosion in very severe environments. Anodized samples resulted to be very resistant in bromides environments, however, as all the surface treatments, anodic oxidation is very affected by surface scratches that may be caused by improper installation of titanium products. For this reason, a second treatment, suitable for local recovery of the oxide layer was developed. This treatment is based on chemical oxidation and does not require the application of any current.

\section{$\underline{\text { Experimental procedure }}$}

\section{Materials}

Square samples $19 \times 19 \times 1.6 \mathrm{~mm}$ were cut from a titanium (ASTM grade 2) plate, and polished with 100 and 300 grit $\mathrm{SiC}$ paper. To remove possible surface contaminations, the specimens were degreased with EtOH in ultrasonic bath for 4 minutes, then rinsed in distilled water with the same ultrasound exposure.

\section{$\underline{\text { Anodic oxidation }}$}

Anodization treatments were conducted in two different regimes: fixed current density, for samples anodized up to $120 \mathrm{~V}$ and constant voltage ramp for samples anodized from $120 \mathrm{~V}$ to $200 \mathrm{~V}$. In the first case the current was supplied by an AimTTi PLH120 DC power supply, able to operate up to 
$120 \mathrm{~V}$ and $0.75 \mathrm{~A}$; in the second case a custom pre-industrial implant with three rectifiers of $150 \mathrm{~V}$ each and a current limit of 10 A was used.

For sample anodized in galvanostatic condition, current was kept at $20 \mathrm{~mA} \cdot \mathrm{cm}^{-2}$ until the achievement of $10 \mathrm{~V}-20 \mathrm{~V}-40 \mathrm{~V}-60 \mathrm{~V}-80 \mathrm{~V}-120 \mathrm{~V}$. For sample anodized at constant potential ramp, the ramp was set to reach $120 \mathrm{~V}-150 \mathrm{~V}$ and $200 \mathrm{~V}$ in two minutes, to investigate the effect of a longer ramp; the anodization at $200 \mathrm{~V}$ was repeated with 10 minutes ramp.

All the anodization treatments were conducted in $\mathrm{H}_{2} \mathrm{SO}_{4} 0.5 \mathrm{M}$ electrolyte at ambient temperature.

\section{Chemical oxidation}

Chemical oxidation was carried out in $\mathrm{NaOH} 10 \mathrm{M}$ accordingly to the works of Krupa et al. [24]. Treatment time are reported to greatly affect the obtained oxide, for this reason the treatment was perform for $1 \mathrm{~h}-6 \mathrm{~h}-12 \mathrm{~h}-18 \mathrm{~h}-24 \mathrm{~h}$ and $72 \mathrm{~h}$.

\section{Testing procedure}

After surface treatment, each sample was rinsed with distilled water in ultrasonic bath for 4 minutes to remove possible deposits from the surface. Oxides film thicknesses were then measured with indirect spectrophotometric technique [20]. For sample exceeding the technique thickness range, sacrificial samples were produced, cut, and gold sputtered to observe their cross section with scanning electron microscope SEM StereoScan 360.

The presence of crystalline structure in the oxides was detected using XRD technique with a diffractometer model Phillips PW 1830, able to generate a $\mathrm{Cu}-\mathrm{K} \alpha$ radiation with a wavelength of $0.154 \mathrm{~nm}$. This technique does not allow the measurement of absolute crystalline fraction, but it is able to determine if anatase or rutile crystalline phases are present in more than $2 \%$ fraction and, through Spurr-Meyer equation, the relative amount of each crystalline phase. [25]

Furthermore, samples corrosion resistance to bromides were characterized with potentiodynamic tests performed with MetroOhm Autolab potentiostat M204. Open circuit potential (OCP) was recorded after $1 \mathrm{~h}$ of sample exposition to the testing solution. Then potential was scanned from $100 \mathrm{mV}$ below the OCP up to $9 \mathrm{~V}$ at $20 \mathrm{mV} / \mathrm{min}$. Anodic current and potential difference between metal and reference electrode were registered with Nova ${ }^{\circledR} 2.1 .1$ software. Reference electrode used was $\mathrm{Ag} / \mathrm{AgCl}$. Tests were conducted in $1 \mathrm{~L}$ cell, filled with $\mathrm{NH}_{4} \mathrm{Br} 0.5 \mathrm{M}$, that is reported to cause localized breakdown of titanium passive layer [26], as the duration didn't exceed 8 hours, no sealing was necessary and neither chemical $(\Delta \mathrm{pH} \approx 0.05)$ nor physical $\left(\Delta \mathrm{T} \approx 2^{\circ} \mathrm{C}\right)$ deviations were detected. In order to ensure repeatability, at least three measurements were made for each treatment procedure.

\section{$\underline{\text { Results and discussion }}$}

Oxide thickness and morphology

The oxides thicknesses of anodized samples, obtained with indirect spectrophotometric measurements or direct SEM observation, are reported in Table 1 together with anatase fraction over the total crystalline phase.

$\mathrm{Up}$ to $60 \mathrm{~V}$ the oxide is completely amorphous. From $80 \mathrm{~V}$ some anatase appears, increasing anodizing potential leads to an increase of crystalline fraction and a progressive transformation and of anatase phase into rutile phase, at $200 \mathrm{~V}$ the amount of anatase in the total crystalline fraction is between $7 \%$ and $10 \%$, depending on the potential ramp imposed for oxide formation.

The increase in rutile fraction increasing ramp time is expected due to the longer time given to the oxide to rearrange and transform anatase phase into rutile phase, moreover the higher total current used in the process justify the higher thickness of the oxide anodized for 10 minutes. It is also important to notice that oxide thickness increases of two order of magnitude passing from $10 \mathrm{~V}$ anodizing potential to $200 \mathrm{~V}$. 
Surface morphology deeply changes increasing anodizing potential (Figure 1). Up to $80 \mathrm{~V}$ the surface is flat and the only morphology detectable is due to polishing. At $120 \mathrm{~V}$ some nanopores start to appear. At $150 \mathrm{~V}$ the surface is fully covered with nanopores and going further with anodizing potential induce a morphology transformation passing from nanoporous to nanogrooved.

Table 1-Anodized sample oxide thickness and anatase fraction.

\begin{tabular}{|c|c|c|}
\hline Anodizing conditions & Oxide Thickness & Anatase fraction, $X_{a}$ \\
\hline $10 \mathrm{~V} \quad\left(20 \mathrm{~mA} / \mathrm{cm}^{2}\right)$ & $40 \mathrm{~nm}$ & Amorphous oxide \\
\hline $20 \mathrm{~V} \quad\left(20 \mathrm{~mA} / \mathrm{cm}^{2}\right)$ & $60 \mathrm{~nm}$ & Amorphous oxide \\
\hline $40 \mathrm{~V} \quad\left(20 \mathrm{~mA} / \mathrm{cm}^{2}\right)$ & $80 \mathrm{~nm}$ & Amorphous oxide \\
\hline $60 \mathrm{~V} \quad\left(20 \mathrm{~mA} / \mathrm{cm}^{2}\right)$ & $120 \mathrm{~nm}$ & Amorphous oxide \\
\hline $80 \mathrm{~V} \quad\left(20 \mathrm{~mA} / \mathrm{cm}^{2}\right)$ & $160 \mathrm{~nm}$ & 1 \\
\hline $120 \mathrm{~V}\left(20 \mathrm{~mA} / \mathrm{cm}^{2}\right)$ & $220 \mathrm{~nm}$ & 0.93 \\
\hline $150 \mathrm{~V}$ (2 min ramp) & $600 \mathrm{~nm}$ & 0.59 \\
\hline $200 \mathrm{~V}(2 \mathrm{~min}$ ramp $)$ & $1500 \mathrm{~nm}$ & 0.10 \\
\hline $200 \mathrm{~V}(10 \mathrm{~min}$ ramp $)$ & $4000 \mathrm{~nm}$ & 0.07 \\
\hline
\end{tabular}
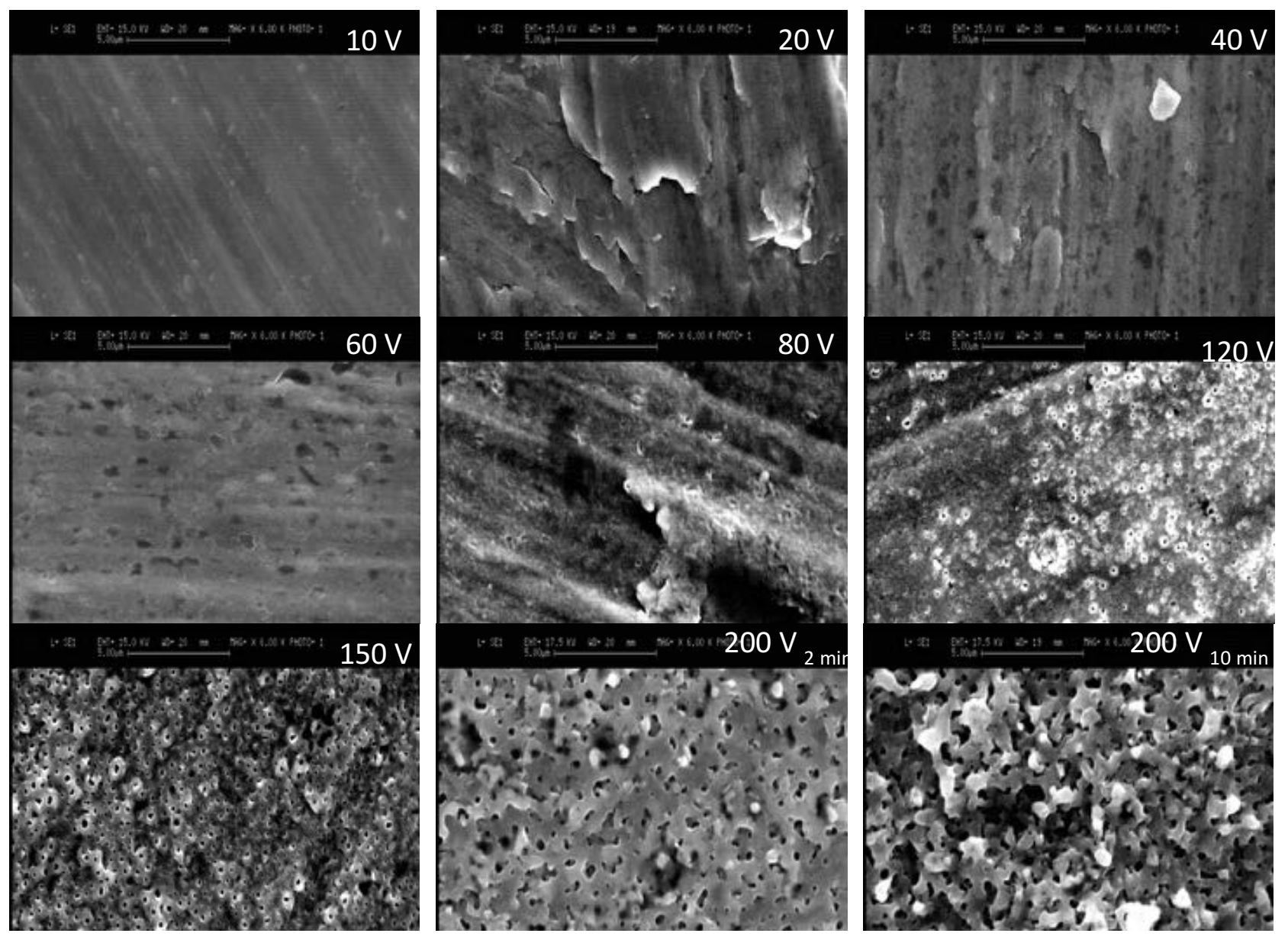

Figure 1 Surface morphology of anodized samples. 
Surface morphology of chemically oxidized samples is different from anodized ones and shows cracks wide from tens to hundreds of nanometers depending on oxidation condition. An example of chemically oxidized surface is visible in Figure 2. The higher the treatment time the wider the cracks in the oxide.

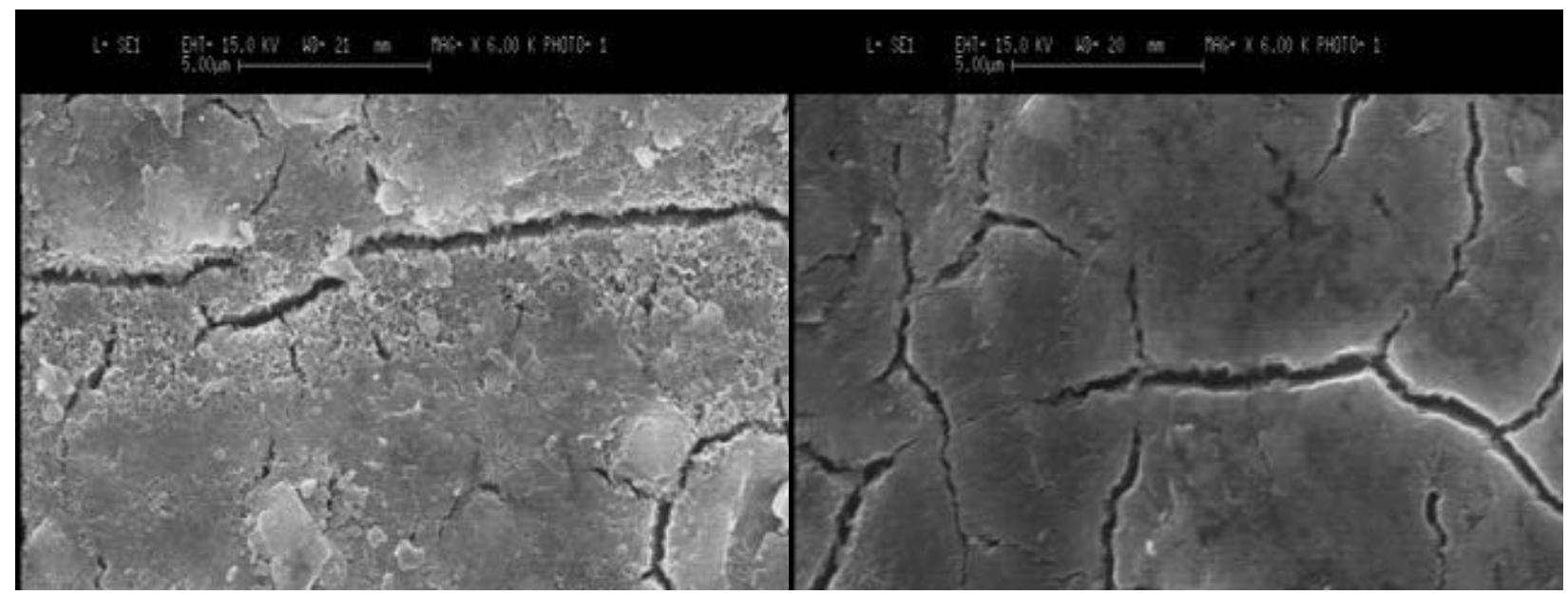

Figure 2 - Surfaces of samples chemically oxidized in $\mathrm{NaOH} 60^{\circ} \mathrm{C}$ for $18 \mathrm{~h}$ (left) and $24 \mathrm{~h}$ (right).

Oxide thickness obtained with chemical oxidation treatment varies with treatment time; direct observations of the cross section of locally cracked oxide showed that the order of magnitude passes from hundreds of nanometers for shorter treatments to one micron and a half for longer treatments, in Figure 3 an example of cross section of cracked oxide is visible.

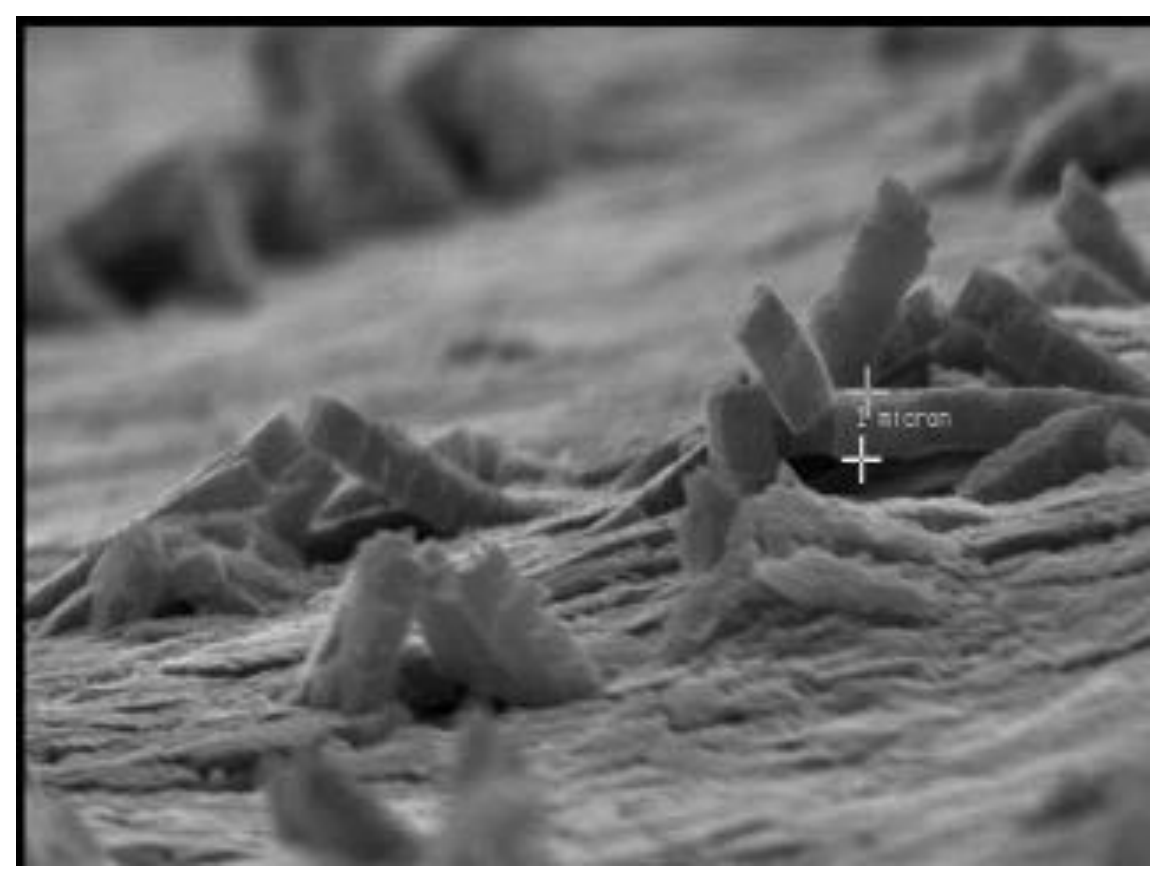

Figure 3 Oxide cross section of sample treated for $24 \mathrm{~h}$ in $\mathrm{NaOH} 60^{\circ} \mathrm{C}$. 
Corrosion resistance

In Figure 4 free corrosion potential $\left(\mathrm{E}_{\text {corr }}\right)$ and breakdown potential are reported with error bars referred to at least three different measurement per condition. While free corrosion potential does not show substantial changes from non-treated to anodized sample, oxide breakdown potential increase of at least $2 \mathrm{~V}$ for each potential. Between samples anodized at potential lower than $120 \mathrm{~V}$, in galvanostatic condition, the $80 \mathrm{~V}$ perform slightly better but the difference with the other sample is moderate. Samples anodized in ASD condition show much higher localized corrosion potential, where no potential is reported the oxide did not show any localized corrosion up to $9 \mathrm{~V}$. Although ASD samples show porous surface, literature reports the existence of an inner compact barrier layer below the outer porous layer [27], for this reason the corrosion resistance of these samples were expected to be at least as high as the one of samples anodized below $100 \mathrm{~V}$.

To compare different potentiodynamic curves, current densities at fixed potential $1 \mathrm{~V}$ and $2 \mathrm{~V}$ were plotted and are visible in Figure 5. Results show that all the anodized samples perform better than the non-treated ones, between samples anodized at potential below $120 \mathrm{~V}$ the $80 \mathrm{~V}$ performs slightly better, confirming the results shown in Figure 4. Current density of samples anodized in ASD regime is comparable to the one of samples anodized in galvanostatic condition. Moreover, the comparison between sample anodized at $200 \mathrm{~V}$ with 2 minutes ramp and 10 minutes ramp show higher current density in the latter condition. This is in agreement with the higher crystallinity developed in the sample anodized for a longer period, in fact, crystalline domains has higher conductivity and, even if they do not affect localized corrosion potential, they increase current density below that potential.

Anodized titanium is reported to have better tribological properties compared to the non-treated one [28], however, corrosion resistance is highly affected by local removal of protective oxide. Chemical oxidation resulted to be a suitable technique to recover scratched oxide without any bulky equipment that cannot be use in field.

The effect on corrosion resistance of titanium exposed to $\mathrm{NaOH} 10 \mathrm{M} 60^{\circ} \mathrm{C}$ for times varying from 1 hour to 72 hours are shown in Figure 6 and Figure 7. From results, the existence of a threshold time can be noticed, after which the corrosion resistance does not increase any more. In the case of $\mathrm{NaOH}$ $60^{\circ} \mathrm{C}$ this threshold is in between from 1 hour to 6 hours; after this period in fact, oxide breakdown potential is almost constant up to 72 hours of treatment. Current density showed negligible variation from non-treated to chemically oxidized sample.

It is important to notice that, while oxide cracks width increase with increasing treatment time, the corrosion resistance does not follow this trend, suggesting that cracks does not connect the underlying metal with the external environment. 


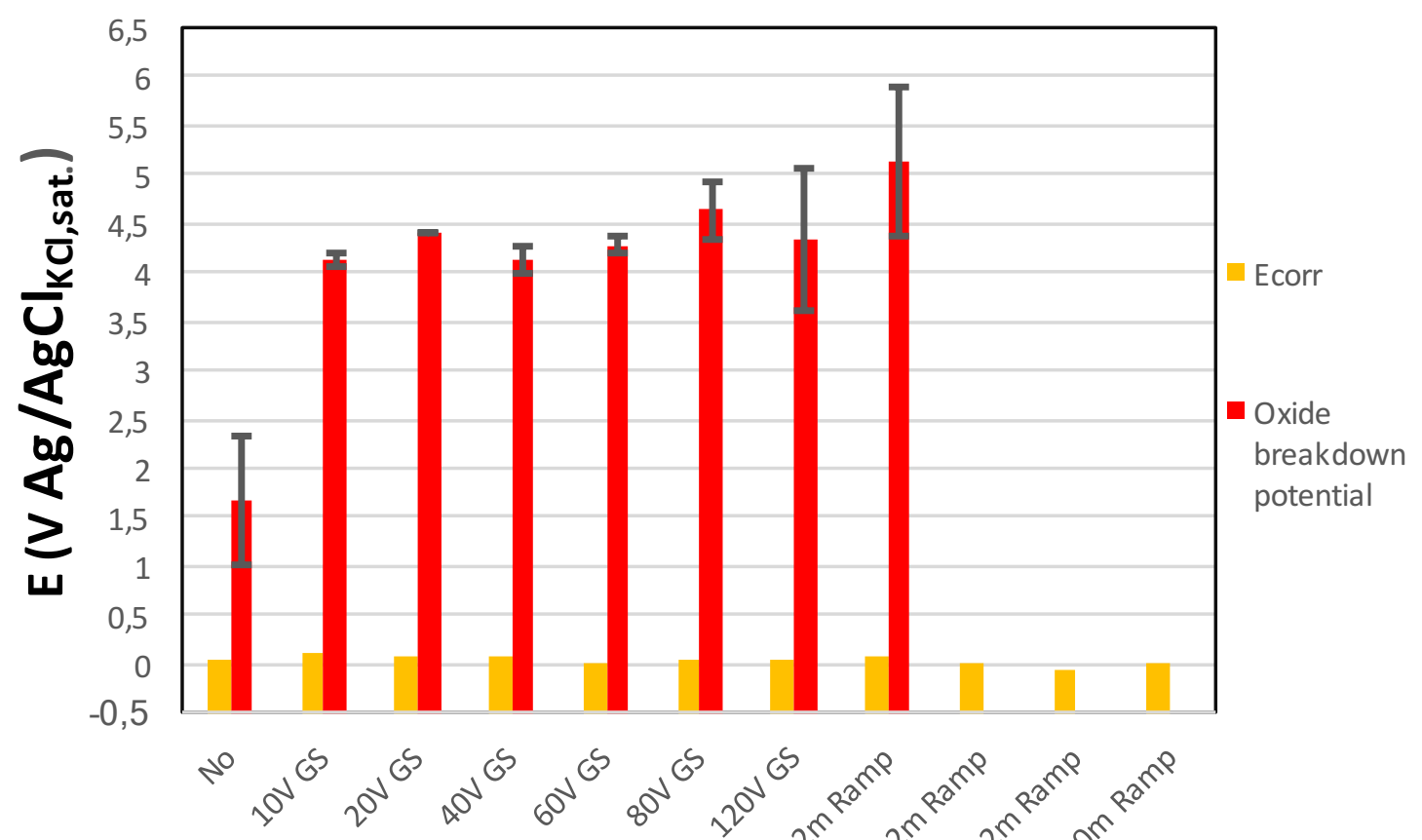

Treatment

Figure 4 Free corrosion potential and oxide breakdown potential of anodized samples in galvanostatic (GS) and constant ramp condition.

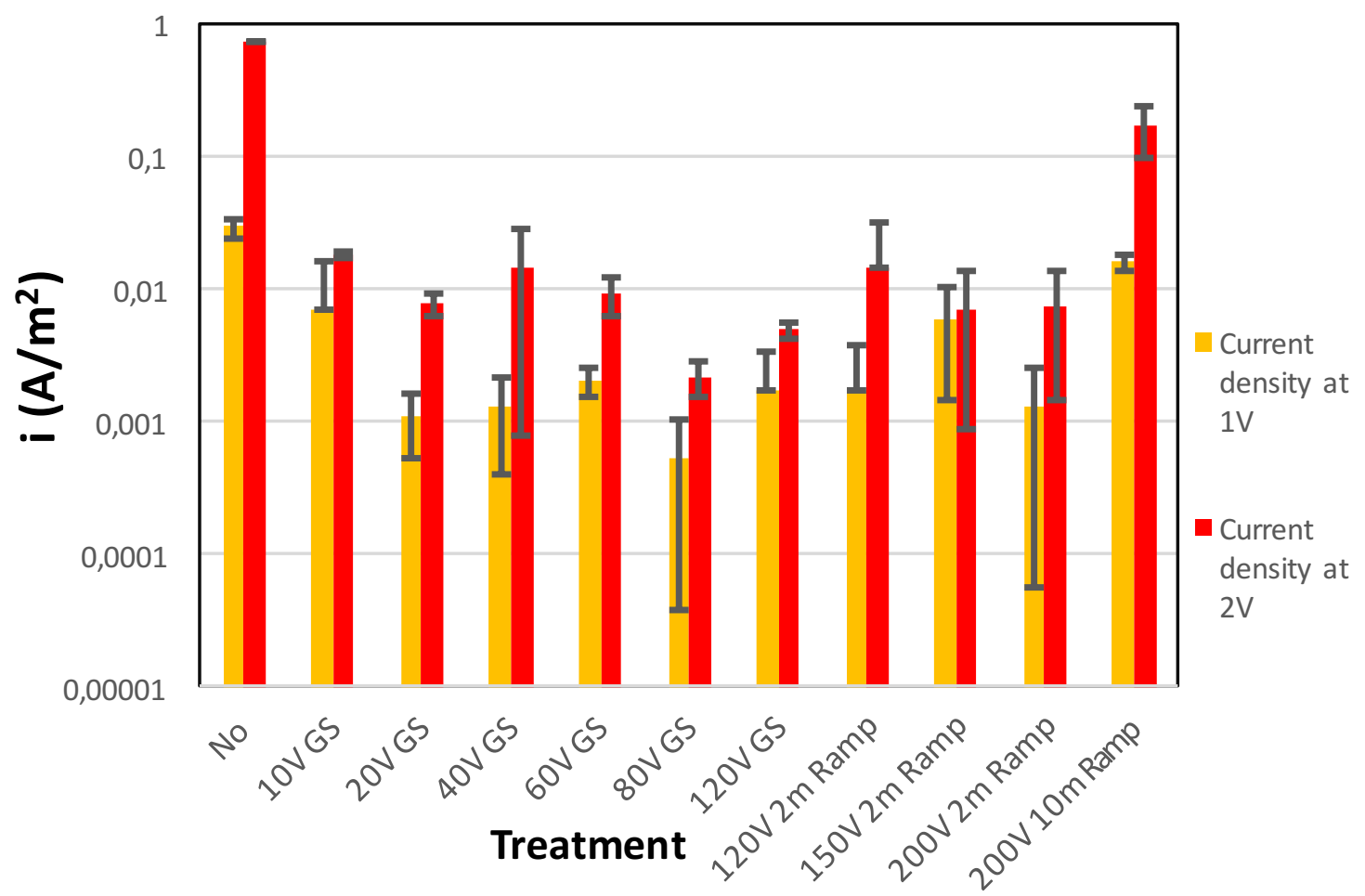

Figure 5 Current density at $1 \mathrm{~V}$ and $2 \mathrm{~V}$ of anodized samples tested in $\mathrm{NH}_{4} \mathrm{Br} 0.5 \mathrm{M}$. 


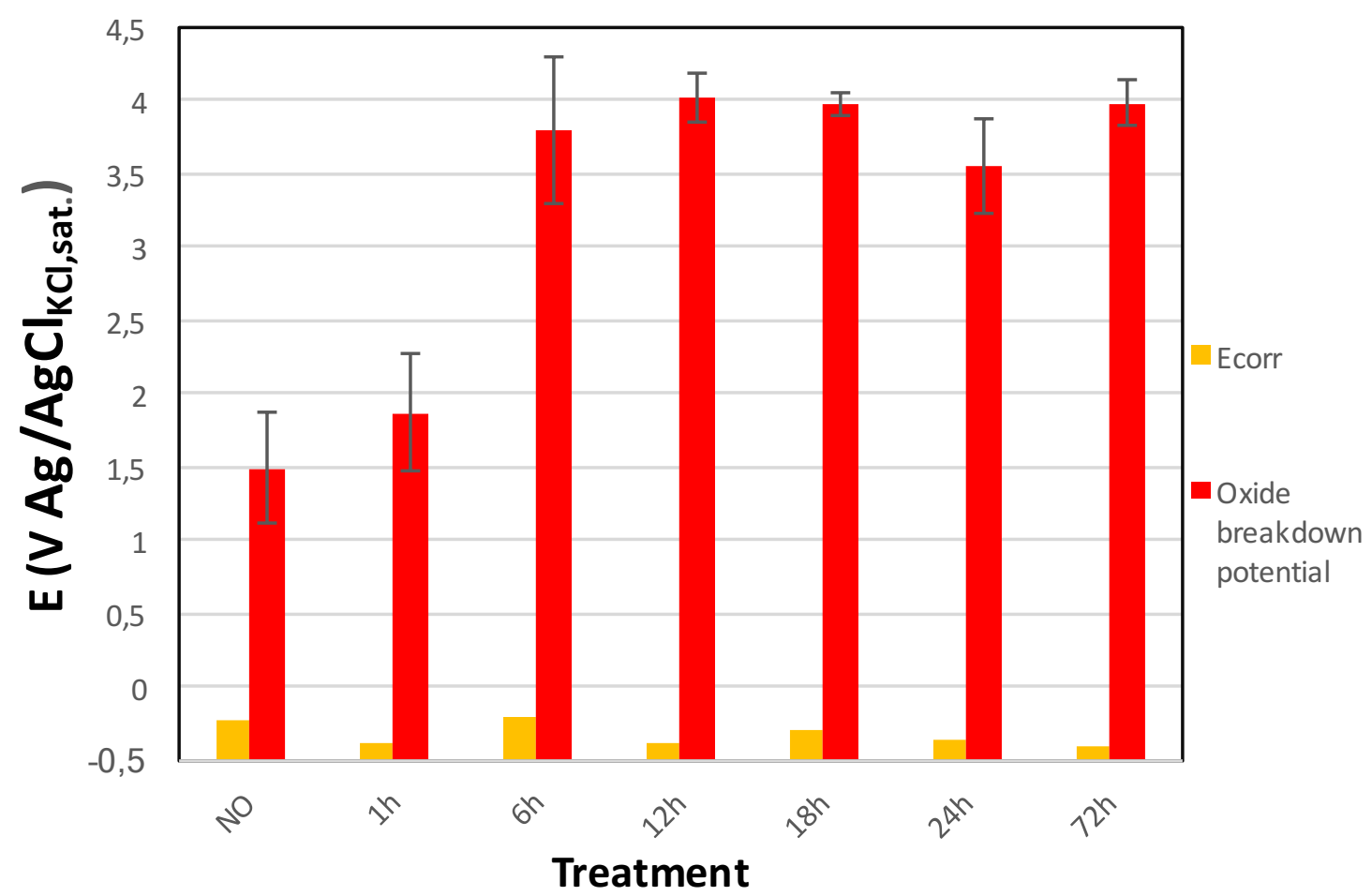

Figure 6 Free corrosion potential and oxide breakdown potential of chemically oxidized samples in $\mathrm{NaOH} 10 \mathrm{M} 60^{\circ} \mathrm{C}$ with different duration.

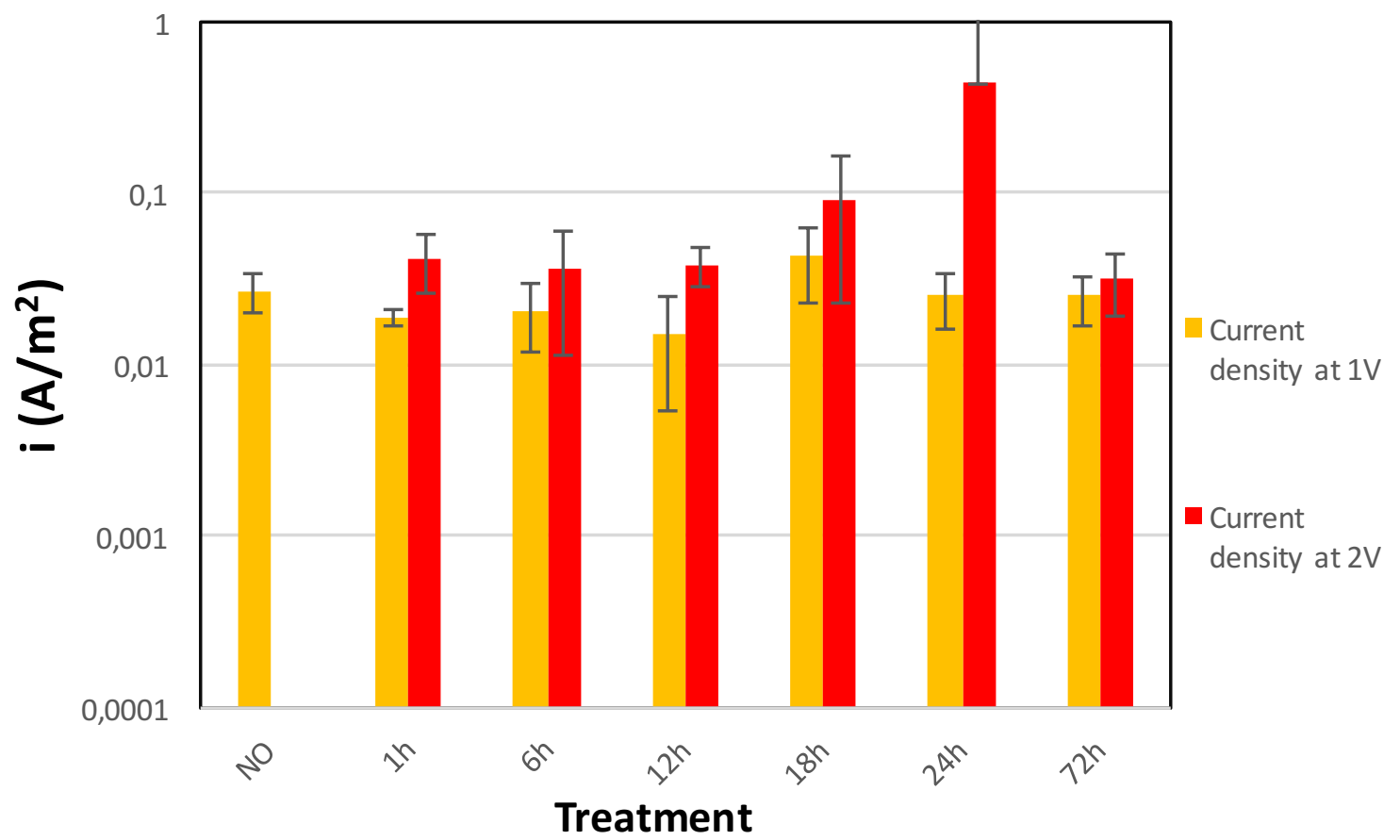

Figure 7 Current density at $1 \mathrm{~V}$ and $2 \mathrm{~V}$ of chemically oxidized samples tested in $\mathrm{NH}_{4} \mathrm{Br} 0.5 \mathrm{M}$. 


\section{Conclusions}

Anodization treatment can be used to improve the corrosion behavior of commercially pure titanium. All the anodization processes tested enhance corrosion resistance of titanium in bromides, increasing oxide breakdown potential by at least $2 \mathrm{~V}$ over the one observed on non-treated titanium. As the higher difference in corrosion resistance is observed between non-treated sample and anodized sample, and just a negligible difference is registered between sample anodized in galvanostatic condition below $120 \mathrm{~V}$, a potential of $20 \mathrm{~V}$ is suggested for a possible industrial application. This treatment produces an oxide thick enough to resist minor wear and requires just a small amount of current. When higher corrosion resistance is needed, it is possible to anodize in ASD regime, in this case a potential of $200 \mathrm{~V}$ reached in a minor is suggested, not only to increase oxide breaking potential, but also to keep low the corrosion current density.

In case of localized removal of the protective oxide, it is possible to perform $\mathrm{NaOH}$ chemical oxidation in-situ. The duration of the treatment increases corrosion resistance of the sample up to the achievement of a plateau, at $60^{\circ} \mathrm{C}$ this plateau is localized between 1 hour and 6 hours, treatments at ambient temperature are expected to delay the plateau and will be object of further studies. The corrosion resistance achieved with this treatment is comparable to the one of sample anodized below $120 \mathrm{~V}$.

In future, other oxidizing species will be investigated together with the influence of lower and higher treatment temperatures.

\section{$\underline{\text { References }}$}

1. Liu Z, Thompson GE (2014) Formation of Porous Anodic Oxide Film on Titanium in Phosphoric Acid Electrolyte. J Mater Eng Perform 24:59-66. doi: 10.1007/s11665-014-1262-7

2. Chang SY, Lin HK, Tsao LC, et al (2014) Effect of voltage on microstructure and corrosion resistance of microarc oxidation coatings on CP-Ti. Corros Eng Sci Technol 49:17-22. doi: 10.1179/1743278213Y.0000000097

3. Boyer RR (1996) An overview on the use of titanium in the aerospace industry. Mater Sci Eng A 213:103-114. doi: 10.1016/0921-5093(96)10233-1

4. Eylon D (1981) Titanium for Energy and Industrial Applications. Metallurgical Society of AIME

5. Virtanen S (2008) Corrosion of biomedical implant materials. Corros Rev 26:147-172.

6. Froes FH, Eylon D, Bomberger HB (1985) Titanium technology: present status and future trends. Titanium Development Association

7. Gorynin IV (1999) Titanium alloys for marine application. Mater Sci Eng A 263:112-116. doi: 10.1016/S0921-5093(98)01180-0

8. Liu J, Alfantazi A, Asselin E (2014) Influence of cupric, ferric, and chloride on the corrosion of titanium in sulfuric acid solutions up to $85^{\circ} \mathrm{C}$. Corrosion 70:29-37.

9. Shoesmith DW, Hardie D, Ikeda BM, Noel JJ (1997) Hydrogen absorption and the lifetime performance of titanium nuclear waste containers. Atomic Energy of Canada Limited

10. Griess JC (1968) Crevice Corrosion of Titanium in Aqueous Salt Solutions. CORROSION 24:96-109. doi: 10.5006/0010-9312-24.4.96

11. Wang ZB, Hu HX, Liu CB, Zheng YG (2014) The effect of fluoride ions on the corrosion behavior of pure titanium in $0.05 \mathrm{M}$ sulfuric acid. Electrochimica Acta 135:526-535. doi: 10.1016/j.electacta.2014.05.055

12. Wang ZB, Hu HX, Zheng YG, et al (2016) Comparison of the corrosion behavior of pure titanium and its alloys in fluoride-containing sulfuric acid. Corros Sci 103:50-65. doi: 10.1016/j.corsci.2015.11.003

13. Schutz RW (2005) Corrosion of Titanium and Titanium Alloys, Corrosion: Materials. ASM International 
14. Alfantazi A, Asselin E, Liu J (2016) The pitting corrosion of titanium in aggressive environments: a review.

15. Beck TR (1973) Pitting of Titanium II. One-Dimensional Pit Experiments. J Electrochem Soc 120:1317-1324.

16. HANDZLIK P, FITZNER K (2013) Corrosion resistance of Ti and Ti-Pd alloy in phosphate buffered saline solutions with and without $\mathrm{H} 2 \mathrm{O} 2$ addition. Trans Nonferrous Met Soc China 23:866-875. doi: 10.1016/S1003-6326(13)62541-8

17. Sathish S, Geetha M, Pandey ND, et al (2010) Studies on the corrosion and wear behavior of the laser nitrided biomedical titanium and its alloys. Mater Sci Eng C 30:376-382. doi: 10.1016/j.msec.2009.12.004

18. Neto GCLB, Silva MAM da, C. Alves J (2009) In vitro study of cell behaviour on plasma surface modified titanium. Surf Eng 25:146-150. doi: 10.1179/174329408X271561

19. Diamanti MV, Pedeferri MP (2007) Effect of anodic oxidation parameters on the titanium oxides formation. Corros Sci 49:939-948. doi: 10.1016/j.corsci.2006.04.002

20. Diamanti MV, Spreafico FC, Pedeferri MP (2013) Production of Anodic TiO2 Nanofilms and their Characterization. Phys Procedia 40:30-37. doi: 10.1016/j.phpro.2012.12.004

21. Mohsen Q, Fadl-Allah SA (2011) Improvement in corrosion resistance of commercial pure titanium for the enhancement of its biocompatibility. Mater Corros 62:310-319. doi: 10.1002/maco.200905534

22. Diamanti MV, Ormellese M, Pedeferri M (2015) Application-wise nanostructuring of anodic films on titanium: a review. J Exp Nanosci 10:1285-1308. doi: 10.1080/17458080.2014.999261

23. Galvis OA, Quintero D, Castaño JG, et al (2015) Formation of grooved and porous coatings on titanium by plasma electrolytic oxidation in $\mathrm{H} 2 \mathrm{SO} 4 / \mathrm{H} 3 \mathrm{PO} 4$ electrolytes and effects of coating morphology on adhesive bonding. Surf Coat Technol 269:238-249. doi: 10.1016/j.surfcoat.2015.02.036

24. Krupa D, Baszkiewicz J, Mizera J, et al (2009) Effect of the heating temperature on the corrosion resistance of alkali-treated titanium. J Biomed Mater Res A 88A:589-598. doi: 10.1002/jbm.a.31900

25. Spurr RA, Myers H (1957) Quantitative Analysis of Anatase-Rutile Mixtures with an X-Ray Diffractometer. Anal Chem 29:760-762. doi: 10.1021/ac60125a006

26. Ittah R, Amsellem E, Itzhak D (2014) Pitting corrosion evaluation of titanium in $\mathrm{NH} 4 \mathrm{Br}$ solutions by electrochemical methods. Int J Electrochem Sci 9:633-643.

27. Jazi MRG, Golozar MA, Raeissi K, Fazel M (2014) Surface Characteristics and Electrochemical Impedance Investigation of Spark-Anodized Ti-6Al-4V Alloy. J Mater Eng Perform 23:1270 1278. doi: 10.1007/s11665-014-0911-1

28. Fazel M, Salimijazi HR, Golozar MA, Garsivaz jazi MR (2015) A comparison of corrosion, tribocorrosion and electrochemical impedance properties of pure Ti and Ti6Al4V alloy treated by micro-arc oxidation process. Appl Surf Sci 324:751-756. doi: 10.1016/j.apsusc.2014.11.030 